\title{
Content Analysis of 2012-2019 FDA Warning Letters and Notices of Violations using the Economic, Clinical, and Humanistic Outcomes (ECHO) Model
}

Namosha Mohite, PharmD Candidate 2021; Vienica Funtanilla, PharmD Candidate 2021; Jagannath Muzumdar, PhD; Taehwan Park, PhD

College of Pharmacy and Health Sciences, St. John's University, Queens, NY

Portions of this research were presented at the American Society of Health-System Pharmacists (ASHP) Midyear Clinical Meeting 2019

\begin{abstract}
Objective: The study purpose was to critically review FDA-issued warning letters (WLs) and notice of violation (NOV) letters against drug companies' from 2012-2019 for economic, clinical, and humanistic (ECHO) claims made in pharmaceutical promotional materials. Specific objectives were to assess the, (1) number of WLs and NOV issued; (2) frequency of WLs and NOV by therapeutic areas; (3) type of communication media cited in WLs or NOV; (4) intended audience for the claims in promotional materials for which the WLs and NOV were issued; and (5) number of WLs and NOV for ECHO claims.

Methods: The quantitative content analysis approach was employed to review WLs and NOVs, obtained from the FDA website, from January 2012-December 2019. A data abstraction form was created based on the published literature on this topic and assessment of the content of WLs and NOVs for 2010. This form was pilot tested on letters issued in 2011. The researchers discussed any unclear question or information presented in the letters. The letters were reviewed three researchers. If there was disagreement between the reviewers, either a fourth reviewer arbitrated on the disagreement or the letter(s) were discussed by the researchers to determine a final classification. ICD-10 codes were used for therapeutic categories in the data collected form. Descriptive statistics, Kappa statistics for interrater reliability, and Cochrane-Armitage test were performed using IBM SPSS Statistics version 24.0

Results: A total of 102 letters were analyzed. Of these, 19 (19\%) were WLs and 83 (81\%) were NOVs. Majority of these letters were issued to manufacturers of therapeutic agents for diseases of the nervous system ( $n=15 ; 14.7 \%)$ and neoplasms ( $n=15 ; 14.7 \%)$. The most commonly cited media for violation was online website ( $n=29 ; 27.1 \%)$. Out of the 153 violations in 102 letters, 92 (60.1\%) were clinical; 13 (8.5\%) humanistic; 2 (1.3\%) were economic; and 46 (30\%) were categorized as 'Others'.

Conclusion: The study found misleading claims of the clinical effectiveness and risk information included in the promotional materials targeted to consumers as well as healthcare providers. Promoting reliable, evidence-based information is important for the health of the public as inadequate information could lead to irrational decision making both on consumer as well as on prescriber side.
\end{abstract}

Keywords: warning letter, untitled letters, notice of violation, FDA, guidance, promotion

\section{Introduction}

On June 24, 2019, the US Food and Drug Administration (FDA)'s Office of Prescription Drug Promotion (OPDP) within the Center for Drug Evaluation and Research (CDER) issued a final guidance titled, "Providing Regulatory Submission in Electronic and NonElectronic Format-Promotional Labeling and Advertising Materials for Human Prescription Drugs." This guidance pertains to submissions of promotional materials for prescription drugs and biological products made by manufacturers, packers, and distributors to the FDA. ${ }^{1}$ The guidance document comes at a time when marketing and promotional expenditures of pharmaceutical companies are at a record high. $^{2}$ Total annual spending by pharmaceutical companies on marketing prescription drugs significantly increased from $\$ 17.7$ billion in 1997 to almost $\$ 30$ billion in $2016 .^{2,3}$ These companies use an array of promotional tools

Corresponding author: Namosha Mohite

PharmD Candidate 2021

College of Pharmacy and Health Sciences,

St. John's University, Queens, NY

Email: namosha.mohite15@stjohns.edu including print advertisements, broadcast advertisements, social media, and other visual aids as part of their product promotion strategy. Claims made by pharmaceutical companies in these promotional tools should ideally be based on scientific evidence since they form the basis of medication prescribing by physicians and utilization by patients. ${ }^{4-6}$

Since this medical marketing influences behaviors and choices of both healthcare professionals (HCPs) and patients and can lead to important treatment outcomes, the OPDP (formerly known as Division of Drug, Marketing, Advertising and Communications), protects the public health by ensuring that all prescription drug promotional labeling and advertising directed to HCPs and consumers are truthful, balanced, and not misleading. ${ }^{7}$ OPDP reviewers examine prescription drug advertising and promotional labeling to ensure that the information contained in these promotional materials are not false or misleading. Failure to comply with the regulatory requirements of the FDA results in FDA enforcement actions. The FDA's most frequently used enforcement mechanisms are advisory communications issued in one of two forms: Warning Letters (WLs) and Untitled letters or Notice of Violation (NOV) letters. 
A Warning Letter identifies a perceived violation, indicates that correction is necessary, specifies if there are any specific actions the FDA wishes the company or individual to take, and provides a number of days (typically 15 days) for the company or individual to take corrective action and respond to the letter. More severe enforcement action can be imposed if no response is submitted to the FDA. However, if the FDA finds that a company or individual adequately responds to a WL and takes appropriate corrective action, FDA may issue a Close-Out Letter stating that the WL violations have been addressed..$^{8,9}$

An Untitled Letter or Notice of Violation (NOV) is an initial FDA correspondence to a regulated party citing infractions of federal food and drug law that the FDA deems to be less severe, therefore, not warranting a WL. An NOV is different from a WL in that, an NOV does not include caution from the FDA that failure to take corrective action could result in enforcement action. Furthermore, an NOV requests, rather than requires, a response. Failure to take action or respond to an NOV, however, could eventually lead to further enforcement action by the agency. ${ }^{8,9}$

To date, a considerable amount of research has been conducted to analyze and understand the content of the WLs and NOVs issued by the FDA. One of the earlier studies by Stewart and Neumann analyzed the WLs and NOVs from 19972001 for economic and Quality of Life (QoL) promotional claims. ${ }^{10}$ A total of 569 FDA letters sent to pharmaceutical companies were reviewed. Unsupported comparative claim or effectiveness, safety, or interchangeability and lack of substantial evidence for QoL claims, were found to be the most commonly cited economic and QoL claims, respectively. The researchers stated that their study was conducted when there were neither formal guidelines describing what constituted a violation nor what level of substantiating evidence was required. Stewart and Neumann concluded that more guidance may be needed to ensure the appropriate use of these claims in drug promotions.

Kamal et al. used the content analysis approach to analyze FDAissued WLs and NOVs from 2000-2006. ${ }^{11}$ A total of 249 WLs ad NOVs were critically evaluated for violations of clinical, pharmacoeconomic, and QoL claims made by manufacturers of pharmaceutical companies. The letters described 806 violations from 107 manufactures. Lack of fair balance, misleading or overstated efficacy claims, and misleading superiority claims were the top three categories with violations. Print aids, sales aids, and television ads were the most frequently cited promotional media used by manufacturers. ${ }^{11}$

Chatterjee et al. employed the content analysis method to review WLs issued by the FDA from 2003-2008. ${ }^{12}$ Misleading claims were broadly classified as clinical, QoL, and economic claims. The study found that misleading clinical outcomes formed the majority of the promotional violations and the majority of the claims in the letters were directed towards physicians. Among those WLs reviewed by Chatterjee et al., letters were primarily directed to manufacturers of cardiovascular drugs followed by anti-microbial and central nervous system drugs. The majority of the claims referenced in the reviewed letters contained promotional materials directed to physicians. ${ }^{12}$

Other studies evaluating FDA-issued WLs and NOVs focused on any one type of violation (clinical, economic or humanistic (QoL)). The ECHO (Economic, Clinical, and Humanistic Outcome) model, first named by Kozma et al., provides comprehensive perspectives to evaluate health care value. ${ }^{13}$ Economic outcomes represent direct, indirect, and intangible costs of health care associated with treatment. Clinical outcomes are medical events that occur as a result of disease or treatment. Humanistic outcomes indicate consequences of disease or treatment on an individual's functional status, health status, or qualify of life. The ECHO model has been utilized in prior literature on FDA-issued letters. For example, a study by Neumann and Bliss investigated FDA's regulatory actions against drug companies' promotions from 2002-2011 focusing on economic violations. ${ }^{14}$ The study objective was to understand the frequency and circumstances the agency considered health economic claims cited in promotions to be false or misleading. The study found that out of 291 letters sent to pharmaceutical companies during the study period, $12 \%$ of the letters cited health economic violation with the most frequent violation being an "implied claim of cost savings to work productivity or functioning."14

Symonds et al. reviewed letters issued 2006-2012 to ascertain the frequency and types of patient-reported outcome (PRO) violations made in pharmaceutical promotional materials (Symonds et al, 2014). Out of the 213 letters, 41 (19\%) letters contained information about PRO infringements. Noticeable spikes in letters were seen when study results were compared to the findings from studies in 2007 (37\%) and 2010 (31\%). ${ }^{15}$

Although this past research has evaluated WLs and NOVs, the publication of the guidance document in June 2019 highlights the need for continued research in critically analyzing FDAissued letters to pharmaceutical companies. ${ }^{1}$ The purpose of this study was to update findings from the previous literature on this topic by reviewing FDA's regulatory actions (i.e. FDAissued WLs and NOVs) against drug companies' from 2012-2019 for clinical, economic, and humanistic claims made in pharmaceutical promotional materials.

Specific study objectives were to explore:

1. The number of Warning Letters (WLS) and Notice of Violations (NOVs) issued from 2012-2019.

2. The frequency of WLS and NOVs by the intended audience for the claims made in promotional materials, the type of communication media cited in the letters, and therapeutic areas for which the WL and NOV were issued. 
3. The number and type of Economic, Clinical, and Humanistic Outcomes (ECHO) claims made in promotional materials for which the WL or NOV were issued.

In particular, to evaluate trend in these outcomes over time, we assessed a change in the outcomes (i.e., number of WLs (or NOVs), type of communication media, therapeutic areas, and type of economic, clinical, and humanistic outcomes claims for which the WLs and NOVs were issued).

\section{Methods}

Study Data: FDA Warning Letters and Notice of Violations

Under the Freedom of Information Act, the FDA issued advisory letters available to the public and freely accessed from the FDA website, https://www.fda.gov/drugs/enforcement-activitiesfda/warning-letters-and-notice-violation-letters-

pharmaceutical-companies. In this study, only drug marketing and advertising WLs and NOVs to pharmaceutical companies issued from January 2012-December 2019 were downloaded and analyzed. That is, other letters such as tobacco retailer warning letters were excluded.

\section{Study Approach and Data Abstraction Form}

The quantitative content analysis approach was employed to review the letters issued by the FDA during January 2012December $2019 .{ }^{16}$ This is a research method defined in brief as, "the systematic assignment of communication content to categories according to rules, and the analysis of relationships involving those categories using statistical methods". ${ }^{16}$

The FDA-issued letters were analyzed using a data abstraction form. This form was developed based on the past literature on this topic, which contains the FDA guidance document published in June 2019 and assessment of the content of WLS for the year 2010. ${ }^{1,10-12,15}$

This data abstraction form helped researchers in analyzing the letters for the following information: date of violation, drug name, company name, product details (e.g., dosage form, dosing information), disease category, type of letter (e.g., warning letter, untitled letter/notice of violation), type of media (e.g. print, broadcast, social media etc.), target audience for the promotional claims (e.g., healthcare providers, consumers such as patients and family members), type of violations, and requested action (e.g., stop the distribution of such promotional materials, reply with the description of their intent and plans to comply with the FDA notification).

The $10^{\text {th }}$ revision of the International Statistical Classification of Diseases and Related Health Problems (ICD-10) was used to classify disease categories for which violations were issued. The violations for which the letters were issued were classified based on the Economic, Clinical, and Humanistic Outcomes (ECHO) model. The ECHO model has been used extensively to describe the value of a pharmaceutical product or service as a combination of traditional and clinical-based outcomes with more contemporary measures of economic efficiency and quality. ${ }^{13}$ Violations not falling within these categories (Economic, Clinical, and Humanistic Outcomes) were classified under "Others" and included issues such as failure to submit under FDA Form 2253, inadequate dissemination of the package insert information, and promotion of an investigational drug.

\section{Data Abstraction and Analysis}

Before analyzing the letters from 2012-2019, the data abstraction form was pilot tested on letters issued in 2011. Three trained researchers reviewed the WLS and NOVs using the data abstraction. If there was a disagreement between the reviewers, either a fourth reviewer arbitrated on the disagreement or all reviewers discussed together to reach a consensus. The fourth researcher collected all completed forms and entered them in the statistical software. Descriptive statistics were run using IBM SPSS Statistics version 24.0. Interrater agreement between two reviewers was evaluated using kappa statistics. ${ }^{17}$ Cochrane-Armitage test was performed to assess a change in the number of WLs (or NOVs), type of communication media, therapeutic areas, and type of economic, clinical, and humanistic outcomes claims for which the WLs and NOVs were issued.

\section{Results}

A total of 102 letters issued to pharmaceutical companies from January 2012-December 2019 were critically reviewed. Out of these, 19 (19\%) were WLs and the remaining 83 (81\%) were NOVs (Table \#1). The highest number of letters, including both WLs and NOVs, were issued in $2012(n=27)$ and the lowest number was issued in $2017(n=5)$ (Table \#1).

Nearly half (46.1\%) of the claims referenced in the issued letters contained promotional materials directed towards consumers, while the remaining $(37.3 \%)$ targeted the healthcare providers (Table \#2). Various forms of communication media were used for promotional materials. Since each letter may have described similar violations in different media types, a total of 107 media violations were reported in 102 letters (Table \#3). The most commonly cited media for violation was online website ( $n=29 ; 27.1 \%$ ) (Table \#3). The second most frequently cited media was sales aid ( $n=18 ; 16.8 \%)$, followed by TV and print ads (for each $n=12 ; 11.2 \%$ ). The most number of violations cited for media were in 2012 ( $n=31 ; 29.0 \%)$ followed by 2013 $(n=23 ; 21.5 \%)$ (Table \#3). No media violations were found for radio and conferences in letters issued from 2012-2019.

Table 4 shows the disease categories for which the WLs or NOV were issued in the study period. Majority of these letters were issued to manufacturers of therapeutic agents for diseases of the nervous system $(n=15 ; 14.7 \%)$ and neoplasms $(n=15$; $14.7 \%)$. These were followed by therapeutic agents for diseases of endocrine, nutritional, and metabolic diseases ( $n=11 ; 10.8 \%)$ 
and mental, behavioral, and neurodevelopmental disorders ( $n=11 ; 10.8 \%)$.

Since each letter contained more than one violation, the 102 letters included a total of 153 violations (Table \#5). Out of these violations, 92 (60.1\%) were related to clinical violations such as misleading or false or unsubstantiated claims on the effectiveness, efficacy, or risk information about the drug; 13 $(8.5 \%)$ were humanistic violations (e.g., misleading claims about improvement in the quality of life); 2 (1.3\%) were economic violations (e.g., supporting cost savings); and 46 $(30.0 \%)$ were categorized as other violations (e.g., inadequate dissemination of the package insert information or failure to submit under form 2253, or promotion of investigational drug). The majority of the violations for "inadequate dissemination of package inserts" is the omission of material facts from the prescribing information (PI). This means that the promotional piece was lacking information from the $\mathrm{PI}$, making the piece scientifically unbalanced and misleading. Another violation under this category is the failure to utilize the most updated PI along with the promotional piece. The greatest number of violations occurred in 2013 ( $n=43 ; 28.1 \%)$, followed by 2012 $(n=39 ; 25.5 \%)$. Among the WLs, although there was a slightly large number of violations in $2012(n=8)$ relative to the numbers in other years (ranging from 0 to 5 ), no other distinct trends were observed.

The study found the highest frequency of clinical outcome related claims. The omission of risk information was the most frequently violated claim $[n=52(51 \%)]$ followed by misleading risk information [31 (30.4\%)] and misleading or overstatement of efficacy [29 (28.4\%)] (Table \#6).

The level of agreement between reviewers was very high (kappa value $\geq 0.8011$ ). Results from Cochrane-Armitage test showed no significant change over time in the number of WLS (or NOVs), type of communication media, therapeutic areas, and type of economic, clinical, and humanistic outcomes claims for which the WLs and NOVs were issued.

\section{Discussion}

The purpose of this study was to critically review FDA's regulatory actions (i.e. FDA-issued WLs and NOVs) against drug companies' from 2012-2019.

In the 8-year study period, the study found that there was a decrease in the total number of letters compared to the total number of letters that were issued in the previous years. ${ }^{11,14,15}$ Similarly, in this same period from 2012-2019, there were a fewer number of WLs (18.6\%) and NOVs (81.4\%) compared to the past published literature. During 2012-2019, there was no significant change in the number of WLs (or NOVs), type of communication media, therapeutic areas, and type of economic, clinical, and humanistic outcomes claims for which the WLs and NOVs were issued. An average of 2 WLs per year was observed in the study period, which is a positive trend since
WLs are more serious (Table \#1). We hypothesize that these decreases in violations are likely due to the release of FDA's OPDP's guidance documents throughout 2011-2019. It is possible that the FDA guidance documents do not only open up communication channels between the FDA and pharmaceutical companies, but also provide opportunities to pharmaceutical companies to correct issues early before the final promotional materials are submitted to the FDA for review. ${ }^{1}$

Contrary to the findings from the work by Chatterjee et al (2012) and Symonds \& Hackford (2014), the present study found that a higher proportion of the issued letters for misleading claims included consumer-directed promotional materials (Table \#2). These findings are similar to the findings of the study by Neumann and Bliss.

Direct-to-consumer advertising (DTCA) has been on the rise since August 1997 when the FDA announced a reinterpretation of its rules on direct-to-consumer (DTC) advertising and relaxed the risk information disclosure requirements for DTCA of prescription drugs. ${ }^{19} \mathrm{~A}$ recently published systematic review of research on patients' and prescribers' perceptions and selfreported behaviors prompted by exposure to DTCA found that the patient-focused studies suggested some potential benefits of exposure to DTCA for patients, such as enhanced health information-seeking, increased requests for appropriate prescriptions (when addressing potential underuse), and perceptions of higher-quality interactions with prescribers. The review also suggested drawbacks, such as patients receiving inappropriate prescriptions for drugs that were not indicated or needed and the potential of interference with medication adherence in some populations, such as those with mental illness. ${ }^{20}$ This review and the findings of the present study highlights the importance of FDA in protecting the public health by ensuring that all prescription drug promotional labeling and advertising directed to consumers (and healthcare providers) are truthful, balanced, and not misleading. ${ }^{21}$

Pharmaceutical companies use an array of promotional tools to market their products. In this study, violations that targeted both consumers and healthcare providers were found most frequently on online websites followed by sales aids, television commercials, and print media (Table \#3). These findings differ from the findings of Kamal et al. In 2008, they found that only $9.7 \%$ of the violations were website violations compared to $27.1 \%$ of website violations in the present study. In the same study, the frequency of violations of print media was $19.2 \%$ compared to $11.2 \%$ of print media violations in the present study. These findings, however, are consistent with the declining trend in print readership and the rise in online promotion. ${ }^{22,23}$

Prescription drug online websites, as a form of drug promotion, are receiving increasing attention as a consumer information source. ${ }^{22,23}$ Consumers prefer going to a drug's website over using other methods to obtain information. ${ }^{23}$ For example, a 
health survey exploring how U.S. adults are using the internet related to health and healthcare found that $59 \%$ reported they have looked online for health information in the past year. ${ }^{24}$ Therefore, social media platforms such as Facebook, Instagram, and Twitter are now heavily used by pharmaceutical companies in promoting prescription drug therapies. This shift from traditional methods to the internet-based DTC has forced the regulatory bodies to make necessary changes in regulations and guidelines. In November 2009, FDA held public hearings to gather comments and questions from our stakeholders (e.g., industry, health care providers, consumers, patient groups, Internet vendors, advertising agencies, and other interested parties) on how FDA can best provide guidance on the promotion of FDA-regulated medical products including prescription drugs using the Internet and social media tools. The public hearing was instrumental in providing an opportunity for our stakeholders to comment. OPDP carefully considered all inputs and since then has released draft guidances that address various topics related to drug advertising on the Internet. ${ }^{21} \mathrm{~A}$ social media webinar was held in July 2014. In addition to these guidance documents, the OPDP has also developed Bad Ad Program, an outreach program designed to help healthcare providers recognize potentially false or misleading prescription drug promotion. However, as pharmaceutical companies shift more resources towards online advertising and away from television, radio, and other traditional channels, the FDA will have to be more stringent in regulating drug information freely available to consumers on the online websites.

As mentioned in the methods, the ICD codes were used to classify disease categories for which violations were issued. The majority of these letters were issued to manufacturers of therapeutic agents for diseases of the nervous system and neoplasms (Table \#4). In 2011-2018, out of the total of 309 novel drugs approved by the CDER, the top two categories with respect to number of new drug approvals were neoplasms (120 novel drugs) and diseases of the nervous system (25 novel drugs). ${ }^{25,26}$ Depending on the trends of novel drug approvals, future research can focus specifically on certain disease categories.

With respect to the type of violations, the study findings were consistent with the findings of previous studies. ${ }^{10-12,15}$ The most violations made were clinical claims followed by humanistic and economic claims (Table \#5). Within the clinical claims, 'misleading or overstatement of efficacy,' 'omission or misleading of risk information,' and 'false and misleading statements' were the most cited reasons of violations (Table \#6). Pharmaceutical companies target audiences by promoting their products as efficacious and fail to provide balanced claims regarding efficacy and safety. This is due to the marketing standpoint that when a drug is promoted to the public, the main concern that both consumers and HCPs have is the drug's efficacy. ${ }^{27}$
The main argument from proponents who promote health information directly to consumers is that it provides valuable information to consumers, which helps with good health care decisions. Critics' main argument against promoting health information directly to consumers is that the information provided by drug makers is an overstatement of the effects and/or a misinterpretation of the risks to influence drug sales, which fail to provide objective health information in the best interest of consumers. ${ }^{22}$ Therefore, it is important that drug makers recognize the significance of communicating truthful, reliable, credible, scientific information to the target audience to protect public health.

\section{Limitations}

Although the study revealed important findings, some findings were consistent with the previously published literature and others were consistent with the current trends in drug promotion. However, some limitations of this study need to be acknowledged. Some letters did not contain attachments of the promotional materials being questioned, so the researchers could not specify the target audience for the promotional materials and a third category of "unspecified" audiences had to be created. Although the interrater reliability was high and differences were discussed among the researchers to reach a consensus, there is a possibility of discrepancy in how the letters were interpreted. Lastly, since the evaluation was conducted on letters issued from 2012-2019, the study findings can only be generalized to this time frame.

\section{Conclusion}

The total number of letters during 2012-2019 was smaller than that issued in the previous years. This decrease indicates the increasing surveillance of the FDA to make sure that they protect the health of the public and the responsible efforts of drug manufacturers to follow the guidance issued by the FDA regarding promotional materials and advertising of pharmaceutical products. As healthcare professionals, prescribers and pharmacists, should keep up to date about these WLs and NOVs as it might take a long time before the violations are corrected and reflected in new promotional materials or product labeling. On the consumer end, it is important for patients to consult their physicians or pharmacists before making any decision regarding their drug therapy. With the rise in social media and other online platforms, researchers need to evaluate FDA issued letters on a continuous basis and at regular intervals.

\section{Acknowledgements: None \\ Funding/support: None}

Conflicts of Interest: We declare no conflicts of interest or financial interests that the authors or members of their immediate families have in any product or service discussed in the manuscript, including grants (pending or received), employment, gifts, stock holdings or options, honoraria, consultancies, expert testimony, patents and royalties. 


\section{References}

1. US Food and Drug Administration Center for Drug Evaluation and Research (CDER) Center for Biologics Evaluation and Research (CBER) June 2019. Providing Regulatory Submissions in Electronic and NonElectronic Format - Promotional Labeling and Advertising Materials for Human Prescription Drugs. Available at https://www.fda.gov/regulatoryinformation/search-fda-guidancedocuments/providing-regulatory-submissionselectronic-and-non-electronic-format-promotionallabeling-and accessed on May 24th 2020.

2. Schwartz, Lisa M., and Steven Woloshin. "Medical marketing in the United States, 1997-2016." Jama 321.1 (2019): 80-96

3. Foley A. January $9^{\text {th }}$ 2019. Big Pharma spent an additional $\$ 9.8$ billion on marketing in the past 20 years. It worked. Available at URL https://qz.com/1517909/big-pharma-spent-anadditional-9-8-billion-on-marketing-in-the-past-20years-it-worked/ accessed on June $17^{\text {th }} 2020$.

4. Datta, A., \& Dave, D. (2017). Effects of physiciandirected pharmaceutical promotion on prescription behaviors: longitudinal evidence. Health economics, 26(4), 450-468.

5. Wood, S. F., Podrasky, J., McMonagle, M. A., Raveendran, J., Bysshe, T., Hogenmiller, A., \& FughBerman, A. (2017). Influence of pharmaceutical marketing on Medicare prescriptions in the District of Columbia. PloS one, 12(10), e0186060.

6. Alves, T. L., Lexchin, J., \& Mintzes, B. (2019). Medicines information and the regulation of the promotion of pharmaceuticals. Science and Engineering Ethics, 25(4), 1167-1192.

7. US Food and Drug Administration Center for Drug Evaluation and Research (CDER) Center for Biologics Evaluation and Research (CBER) May 2020. Office of Prescription Drug Promotion. Available at URL https://www.fda.gov/about-fda/center-drugevaluation-and-research-cder/office-prescriptiondrug-promotion-opdp accessed on June $17^{\text {th }} 2020$.

8. US Food and Drug Administration December 2017. Regulatory Procedures Manual. Chapter \# 4: Advisory Actions. Available at URL

https://www.fda.gov/inspections-complianceenforcement-and-criminal-

investigations/compliance-manuals/regulatoryprocedures-manual accessed on June 30 2020.

9. US Food and Drug Administration October 2019-b. Advisory Action Letters. Available at URL https://www.fda.gov/animal-veterinary/complianceenforcement/advisory-action-letters accessed on June $17^{\text {th }} 2020$.
10. Stewart, K. A., \& Neumann, P. J. (2002). FDA actions against misleading or unsubstantiated economic and quality-of-life promotional claims: an analysis of warning letters and notices of violation. Value in Health, 5(5), 390-397.

11. Kamal, K. M., Desselle, S. P., Rane, P., Parekh, R., \& Zacker, C. (2009). Content analysis of FDA warning letters to manufacturers of pharmaceuticals and therapeutic biologicals for promotional violations. Drug information journal: DIJ/Drug Information Association, 43(4), 385-393.

12. Chatterjee S, Patel HK, Sansgiry SS. An analysis of the warning letters issued by the FDA to pharmaceutical manufacturers regarding misleading health outcomes claims. Pharmacy Practice (Internet) 2012 Oct-Dec; 10(4):194-198.

13. Kozma, C. M., Reeder, C. E., Schulz, R. M. (1993). Economic, clinical, and humanistic outcomes: $A$ planning model for pharmacoeconomic research. Clinical therapeutics, 15(6), 1121-1132.

14. Neumann, P. J., \& Bliss, S. K. (2012). FDA actions against health economic promotions, 2002-2011. Value in Health, 15(6), 948-953.

15. Symonds, T., Hackford, C., \& Abraham, L. (2014). A review of FDA warning letters and notices of violation issued for patient-reported outcomes promotional claims between 2006 and 2012. Value in health, 17(4), 433-437.

16. Riffe, D., Lacy, S., Fico, F., \& Watson, B. (2019). Analyzing media messages: Using quantitative content analysis in research. Routledge

17. Landis, J. R., \& Koch, G. G. (1977). The measurement of observer agreement for categorical data. Biometrics, 33(1), 159-174.

18. Kozma, C. M., Reeder, C. E., \& Schulz, R. M. (1993). Economic, clinical, and humanistic outcomes: a planning model for pharmacoeconomic research. Clinical therapeutics, 15(6), 1121-32.

19. Applequist, J., \& Ball, J. G. (2018). An updated analysis of direct-to-consumer television advertisements for prescription drugs. The Annals of Family Medicine, 16(3), 211-216.

20. DeFrank, J. T., Berkman, N. D., Kahwati, L., Cullen, K., Aikin, K. J., \& Sullivan, H. W. (2020). Direct-toconsumer advertising of prescription drugs and the patient-prescriber encounter: a systematic review. Health Communication, 35(6), 739-746.

21. US Food and Drug Administration (December, 2020). For Industry: Using Social Media. Available on URL https://www.fda.gov/about-fda/center-drugevaluation-and-research-cder/industry-using-socialmedia accessed on December 6th 2020

22. Huh, J., \& Shin, W. (2014). Trust in prescription drug brand websites: website trust cues, attitude toward the website, and behavioral intentions. Journal of health communication, 19(2), 170-191. 
23. Wymer, W. (2010). Consumer perceptions of prescription drug websites: A pilot study. Health marketing quarterly, 27(2), 173-194.

24. Pew Research Center (February, 2013). The Internet and Health. Available on URL https://www.pewresearch.org/internet/2013/02/12/ the-internet-and-health/ accessed on December 6th 2020

25. Mikulic M. (March, 10, 2020). Statista: Number of novel drugs approved annually by CDER 2008-2019. Available at URL https://www.statista.com/statistics/817534/annualnovel-drug-approvals-by-cder/ accessed on June $17^{\text {th }}$ 2020

26. Shin, Y. E., Kim, S. B., Zheng, Z., Muzumdar, J., \& Wu, W. (2019). PNS243 Review of Patient Reported Outcome (PRO) Measures for Novel Drug Approvals (NDA) in the United States: 2016-2018. Value in Health, 22, S327.

27. Schommer, J. C., Worley, M. M., \& Kjos, A. L. (2014). Decision-making during initiation of medication therapy. Research in Social and Administrative Pharmacy, 10(2), 313-327. 
Table 1. Type letters that were issued in the respective year

\begin{tabular}{|c|c|c|c|c|c|c|c|c|c|}
\hline \multirow[b]{2}{*}{ Type of Letter } & \multicolumn{8}{|c|}{ Year $(\mathrm{N}=102)$} & \multirow[t]{2}{*}{ Total } \\
\hline & $\begin{array}{c}2012 \\
(N=27)\end{array}$ & $\begin{array}{c}2013 \\
(N=24)\end{array}$ & $\begin{array}{c}2014 \\
(N=9)\end{array}$ & $\begin{array}{c}2015 \\
(N=9)\end{array}$ & $\begin{array}{c}2016 \\
(N=11)\end{array}$ & $\begin{array}{c}2017 \\
(N=5)\end{array}$ & $\begin{array}{c}2018 \\
(N=7)\end{array}$ & $\begin{array}{c}2019 \\
(N=10)\end{array}$ & \\
\hline Warning Letter & 3 & 3 & 0 & 2 & 3 & 3 & 2 & 3 & 19 \\
\hline $\begin{array}{c}\text { Untitled Letter/ } \\
\text { Notice of } \\
\text { Violation }\end{array}$ & 24 & 21 & 9 & 7 & 8 & 2 & 5 & 7 & 83 \\
\hline
\end{tabular}

Table 2. Intended audience for the claims in promotional materials for which the warning letters and notice of violations were issued in the respective year

\begin{tabular}{|c|c|c|c|c|c|c|c|c|c|}
\hline \multirow[b]{2}{*}{$\begin{array}{l}\text { Type of } \\
\text { Audience }\end{array}$} & \multicolumn{8}{|c|}{ Year $(\mathrm{N}=102)$} & Total \\
\hline & $\begin{array}{c}2012 \\
(N=27)\end{array}$ & $\begin{array}{c}2013 \\
(N=24)\end{array}$ & $\begin{array}{c}2014 \\
(N=9)\end{array}$ & $\begin{array}{c}2015 \\
(N=9)\end{array}$ & $\begin{array}{c}2016 \\
(N=11)\end{array}$ & $\begin{array}{c}2017 \\
(N=5)\end{array}$ & $\begin{array}{c}2018 \\
(N=7)\end{array}$ & $\begin{array}{c}2019 \\
(N=10)\end{array}$ & \\
\hline Healthcare Providers & 11 & 9 & 5 & 4 & 2 & 2 & 4 & 1 & 38 \\
\hline Consumers & 15 & 10 & 4 & 1 & 4 & 2 & 3 & 8 & 47 \\
\hline Unspecified & 1 & 5 & 0 & 4 & 5 & 1 & 0 & 1 & 1 \\
\hline
\end{tabular}

Table 3. Type and number of times media was cited in promotional materials for which the warning letters and notice of violations were issued in the respective year ${ }^{a}$

\begin{tabular}{|c|c|c|c|c|c|c|c|c|c|}
\hline \multirow{2}{*}{ Type of Media } & \multicolumn{9}{|c|}{ Year (N=107) } \\
\cline { 2 - 10 } & $\begin{array}{c}2012 \\
(\mathrm{~N}=31)\end{array}$ & $\begin{array}{c}2013 \\
(\mathrm{~N}=23)\end{array}$ & $\begin{array}{c}2014 \\
(\mathrm{~N}=9)\end{array}$ & $\begin{array}{c}2015 \\
(\mathrm{~N}=9)\end{array}$ & $\begin{array}{c}2016 \\
(\mathrm{~N}=11)\end{array}$ & $\begin{array}{c}2017 \\
(\mathrm{~N}=6)\end{array}$ & $\begin{array}{c}2018 \\
(\mathrm{~N}=8)\end{array}$ & $\begin{array}{c}2019 \\
(\mathrm{~N}=10)\end{array}$ & Total \\
\hline TV & 2 & 1 & 0 & 1 & 5 & 1 & 0 & 2 & 12 \\
\hline Radio & 0 & 0 & 0 & 0 & 0 & 0 & 0 & 0 & 0 \\
\hline Print Ads & 1 & 8 & 1 & 0 & 0 & 0 & 0 & 2 & 12 \\
\hline Social Media & 0 & 0 & 1 & 1 & 1 & 0 & 1 & 1 & 5 \\
\hline Brochures & 3 & 2 & 0 & 0 & 0 & 0 & 0 & 0 & 5 \\
\hline Booklets & 0 & 1 & 0 & 0 & 0 & 0 & 0 & 0 & 1 \\
\hline Sales Aid & 6 & 2 & 3 & 3 & 1 & 1 & 1 & 1 & 18 \\
\hline Conference & 0 & 0 & 0 & 0 & 0 & 0 & 0 & 0 & 0 \\
\hline Sale Reps & 2 & 0 & 0 & 0 & 0 & 0 & 1 & 0 & 3 \\
\hline Exhibit pane/booth & 3 & 1 & 0 & 1 & 1 & 2 & 2 & 0 & 10 \\
\hline Online Website & 10 & 5 & 0 & 3 & 2 & 2 & 3 & 4 & 29 \\
\hline Others & 4 & 3 & 4 & 0 & 1 & 0 & 0 & 0 & 12 \\
\hline
\end{tabular}

a Several letters included multiple types of media. 
Table 4. Disease categories for which the warning letters and notice of violations were issued in the respective year

\begin{tabular}{|c|c|c|c|c|c|c|c|c|c|}
\hline \multirow[b]{2}{*}{ Disease category } & \multicolumn{8}{|c|}{ Year $(\mathrm{N}=102)$} & \multirow[b]{2}{*}{ Total } \\
\hline & $\begin{array}{c}2012 \\
(\mathrm{~N}=27)\end{array}$ & $\begin{array}{c}2013 \\
(N=24)\end{array}$ & $\begin{array}{c}2014 \\
(\mathrm{~N}=9)\end{array}$ & $\begin{array}{l}2015 \\
(\mathrm{~N}=9)\end{array}$ & $\begin{array}{c}2016 \\
(\mathrm{~N}=11)\end{array}$ & $\begin{array}{l}2017 \\
(N=5)\end{array}$ & $\begin{array}{l}2018 \\
(N=7)\end{array}$ & $\begin{array}{c}2019 \\
(N=10)\end{array}$ & \\
\hline Certain Infectious and Parasitic Diseases & 2 & 4 & 2 & 0 & 1 & 0 & 0 & 0 & 9 \\
\hline $\begin{array}{l}\text { Diseases of the Blood and Blood-Forming } \\
\text { Organs and Certain Disorders Involving the } \\
\text { Immune Mechanism }\end{array}$ & 2 & 1 & 0 & 1 & 0 & 0 & 0 & 0 & 4 \\
\hline $\begin{array}{l}\text { Mental, Behavioral, and Neurodevelopmental } \\
\text { Disorders }\end{array}$ & 3 & 2 & 2 & 2 & 0 & 0 & 1 & 1 & 11 \\
\hline Diseases of the Nervous System & 5 & 1 & 2 & 0 & 2 & 2 & 2 & 1 & 15 \\
\hline Diseases of the Eye and Adnexa & 0 & 2 & 0 & 0 & 0 & 0 & 0 & 0 & 2 \\
\hline Diseases of the Skin and Subcutaneous Tissue & 1 & 0 & 0 & 0 & 0 & 0 & 0 & 1 & 2 \\
\hline $\begin{array}{l}\text { Diseases of the Musculoskeletal System and } \\
\text { Connective Tissue }\end{array}$ & 0 & 1 & 0 & 0 & 1 & 0 & 0 & 0 & 2 \\
\hline Diseases of the Genitourinary System & 0 & 0 & 0 & 2 & 1 & 1 & 2 & 2 & 8 \\
\hline Pregnancy, Childbirth, and the Puerperium & 0 & 0 & 0 & 1 & 0 & 0 & 0 & 0 & 1 \\
\hline $\begin{array}{l}\text { Symptoms, Signs, and Abnormal Clinical and } \\
\text { Laboratory Findings, Not Elsewhere Classified }\end{array}$ & 0 & 1 & 0 & 0 & 0 & 0 & 0 & 0 & 1 \\
\hline $\begin{array}{l}\text { Factors Influencing Health Status and Contact } \\
\text { with Health Services }\end{array}$ & 0 & 1 & 0 & 1 & 1 & 0 & 0 & 2 & 5 \\
\hline
\end{tabular}

Table 5. Type and number of violations for which the warning letters and notice of violations were issued in the respective year ${ }^{a}$

\begin{tabular}{|c|c|c|c|c|c|c|c|c|c|}
\hline \multirow[b]{2}{*}{$\begin{array}{c}\text { Type of } \\
\text { Violation }\end{array}$} & \multicolumn{9}{|c|}{ Year $(N=153)$} \\
\hline & $\begin{array}{c}2012 \\
(N=39)\end{array}$ & $\begin{array}{c}2013 \\
(N=43)\end{array}$ & $\begin{array}{c}2014 \\
(N=15)\end{array}$ & $\begin{array}{c}2015 \\
(N=12)\end{array}$ & $\begin{array}{c}2016 \\
(N=15)\end{array}$ & $\begin{array}{c}2017 \\
(N=9)\end{array}$ & $\begin{array}{c}2018 \\
(N=7)\end{array}$ & $\begin{array}{c}2019 \\
(N=13)\end{array}$ & Total \\
\hline Economic & 1 & 1 & 0 & 0 & 0 & 0 & 0 & 0 & 2 \\
\hline Clinical & 26 & 2 & 9 & 8 & 7 & 5 & 6 & 8 & 92 \\
\hline Humanistic & 8 & 4 & 0 & 1 & 0 & 0 & 0 & 0 & 13 \\
\hline Others & 4 & 15 & 6 & 3 & 8 & 4 & 1 & 5 & 46 \\
\hline
\end{tabular}

a Several letters included multiple violations. 
Table 6. Description of violations in the letters issued between 2012-2019

\begin{tabular}{|c|c|}
\hline Type of Violation & Frequency \\
\hline \multicolumn{2}{|l|}{ Economic Violations } \\
\hline $\begin{array}{l}\text { Misleading or unsubstantiated claims of cost-savings, lower drug costs, spending, pricing, } \\
\text { expenditures, expense, affordable }\end{array}$ & 1 \\
\hline $\begin{array}{l}\text { Misleading or unsubstantiated claims made about hospitalization costs, doctor visit, physician visit, } \\
\text { office visit, pharmacist or pharmacy visit }\end{array}$ & 1 \\
\hline \multicolumn{2}{|l|}{ Clinical Violations } \\
\hline Misleading or overstatement of efficacy & 29 \\
\hline Unsubstantiated efficacy claims & 16 \\
\hline Misleading safety claims & 5 \\
\hline Unsubstantiated safety claims & 4 \\
\hline Misleading superiority claims & 19 \\
\hline Unsubstantiated effectiveness claims & 7 \\
\hline Misleading or unsubstantiated claims of comparison of clinical effectiveness & 6 \\
\hline Omission of Risk Information & 52 \\
\hline Misleading Risk Information & 31 \\
\hline Lack of Fair Balance between risks and benefits & 1 \\
\hline Broadening of Indication & 9 \\
\hline Promotion of unapproved use & 9 \\
\hline False and Misleading statements & 9 \\
\hline Promoting a product for use in a vulnerable population & 1 \\
\hline Other & 1 \\
\hline \multicolumn{2}{|l|}{ Humanistic Violations } \\
\hline Misleading or unsubstantiated quality of life (QOL) claims & 4 \\
\hline Misleading or unsubstantiated claims about Health Related Quality of Life (HRQOL) & 7 \\
\hline Misleading or unsubstantiated claims about overall well-being of patients or family members & 1 \\
\hline Misleading or unsubstantiated claims about physical, mental, social functional status & 2 \\
\hline \multicolumn{2}{|l|}{ Other Violations } \\
\hline Failure to submit under FDA Form 2253 & 8 \\
\hline Inadequate dissemination of the package insert information & 28 \\
\hline Lack of References and supporting documents for claims made in the promotional material & 3 \\
\hline Promotion of an investigational drug & 15 \\
\hline
\end{tabular}

